in the paper comprises transmitter-receiver units for the frequency range $38 \cdot 5-42 \cdot 3 \mathrm{Mc}$./sec. for air-to-air and short-range air-to-ground telephonic communication, and somewhat similar units as fitted in Army co-operation aircraft and covering the range $42 \cdot 1-$ $47.9 \mathrm{Mc}$./sec., with additional facilities for telegraphic signalling.

A brief description is also given of the installation, now known to be obsolete, used in an Italian bomber which was shot down on the east coast of England in 1940. As examples of Japanese practice, brief accounts are given of the equipments used in the "Zero" fighters and certain types of Navy bomber.

The paper concludes with a short commentary on the design and lay-out of the various installations examined, and of the materials and components used. Much of this development and production work is undoubtedly very advanced, and the information which the author has collected and reproduced should prove of value to those responsible for the design and manufactur $\ni$ of radio equipment for aircraft.

\section{RESEARCH AND THE IRON AND STEEL INDUSTRY}

SINCE the Heterogeneity of Steel Ingots Research $\$$ Committee started its work in 1924, this aspect of the interests of the Iron and Steel Institute and the British Iron and Steel Federation has progressed continuously. At present, there are in being some twenty-three such research committees of one kind and another, of which the main, in addition to the Ingots Committee itself, are those concerned with the Alloy Steels (1934), Corrosion (1928), and Steel Castings (1934). A review of their work over a period of twenty years was initially prepared by the late Dr. W. H. Hatfield, and has now been issued*. Hatfield's tragic death has removed the one around whom, more perhaps than any other, these committees and their work have revolved.

The data which have been collected during this time have resulted from the joint efforts of the industry itself, the university, governmental and similar institutions, and affords an outstanding example of the fruitfulness of such an association. The present writer, in the past, has not been uncritical, but this publication provides undoubted evidence of the existence of a far more healthy spirit than obtained until comparatively recently, and, further, one which may be believed to be permanent. The ready willing. ness of so many industrial research establishments to assist in, and to further, the work being done in academic laboratories, is also deserving of special mention. In any future developments envisaged for the encouragement of research into the particular problems of the iron and steel industry, it is a matter of first-rate importance that this collaboration should be maintained, and that no aspect of research activity should be neglected.

The essential purpose of the present report, to give a fairly detailed summary of the work already accomplished by the various committees, is very well done, and a most substantial addition to our knowledge of the nature of steels, their manufacture and properties, has resulted. How widespread have been

- Iron and Steel Institute. Special Report No. 29 : Review of the Work of the Joint Research Committees 1924-1943 of the Iron and Steel Institute and the British Iron and Steel Federation. Pp. vii +176 . the interests of these bodies, especially in more recent years, may be illustrated from some of the researches of the Ingots Committee or its offshoots. These have ranged from studies of slag equilibria to the effect of casting speeds; from the use of radioactive materials in the examination of inclusions, to rimming steels. All these are clearly of fundamental importance from the point of view of the technology of the industry, but many are making a by no means unimportant contribution to scientific knowledge in general. In this connexion, it may be sufficient to cite the work on the accurate measurement of the very high temperatures employed in steel-making.

An interesting aspect of the report is the survey of further work already commenced or contemplated. As, from some points of view, the whole scheme has become more and more interesting as time has gone on, these researches will be looked forward to with keen anticipation. F. C. Thompson.

\section{TREATMENT OF SHOCK BY HEAT}

T HE principle of treating traumatic shock by the application of heat has become so well established and has been so much emphasized in first-aid services during the War that the investigations done by A. W. Kay, of the University of Glasgow (Brit. Med. J., 40, Jan. 8), will interest many besides the medical profession.

Mr. Kay has studied the effects of heat on healthy young adults, and he points out that the results cannot be properly applied to patients suffering from traumatic shock; but he thinks that they do suggest that we should study more carefully the effects of heat on shocked people. While the condition known as shock is not yet fully understood, it has been believed, as Mr. Kay points out, that heat helps recovery from shock mainly by relieving the vasoconstriction of the cutaneous blood-vessels and so helping the venous return of the blood. It has only recently been suggested that this vaso-constriction may be a compensatory mechanism and that heat may therefore be harmful.

Mr. Kay's subjects were heated in a hot-air cradle to $38-40^{\circ} \mathrm{C}$. for one hour, ten of them receiving normal saline intravenously and five of them receiving plasma intravenously throughout this period. Three experiments had to be abandoned because of the severe symptoms (headache, nausea, exhaustion) and anxiety produced. Nine cases showed evidence of dehydration (dry tongue, weakness and thirst) and all cases showed general perspiration and increased pulse-rate. Nausea occurred in six cases.

The essential factor suggested as the cause of these troubles is general peripheral dilatation, which caused a lowering of the arterial blood pressure and a rise of venous pressure. Since most accepted forms of treatment of shock aim at raising the blood pressure, and since the subjects of these experiments showed a constant and progressive lowering of the blood pressure, the prolonged use of heat for the treatment of traumatic shock would appear, in Mr. Hay's opinion, to be contraindicated.

An annotation in the same issue of the British Medical Journal gives other references to work on this subject done on man and animals. Further work is clearly required, and it is suggested that intracardiac catheterization might open up a new era in the study of cardiodynamics. 